\title{
$\mathrm{BMC}$
}

Medical Genetics

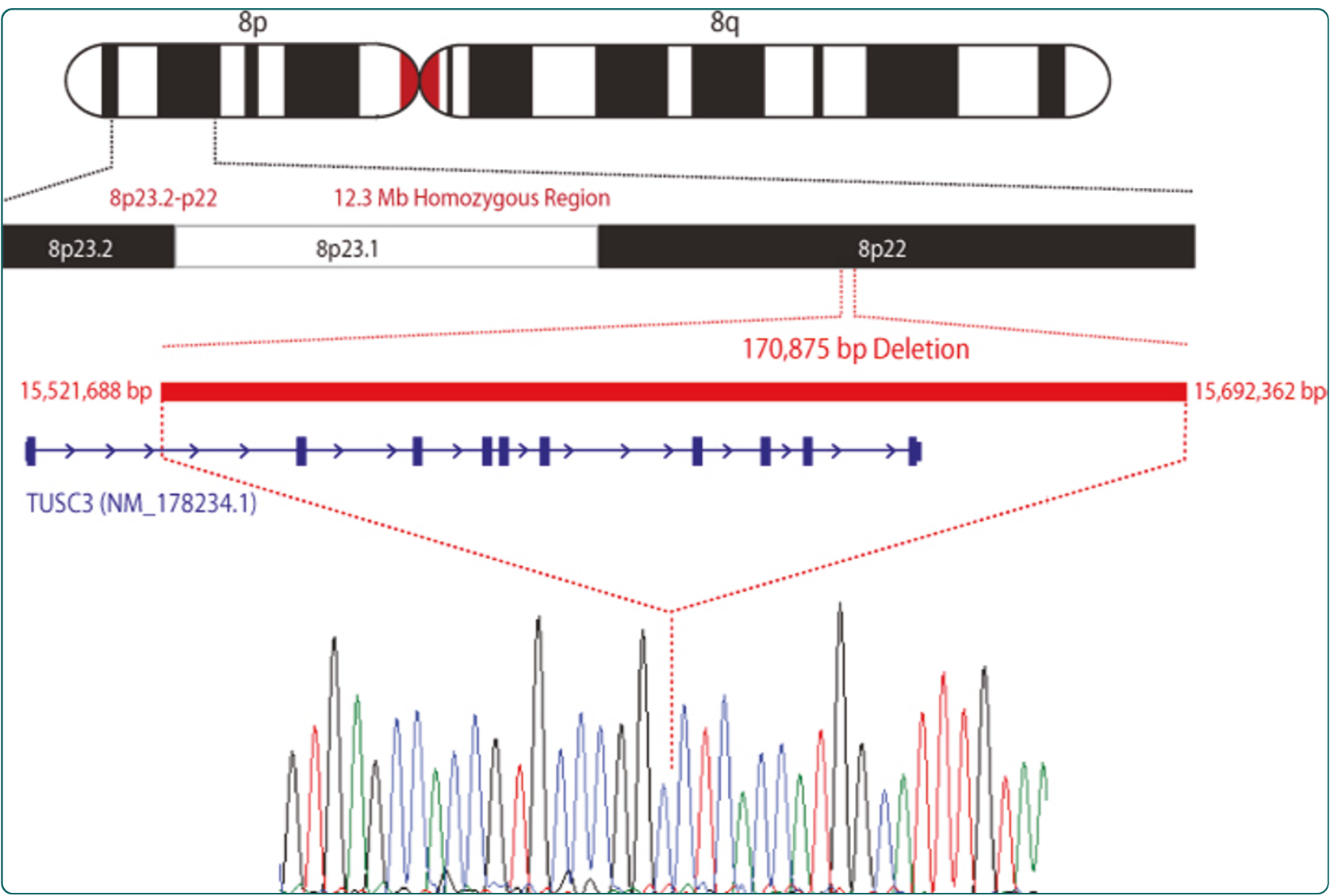

\section{A novel deletion mutation in the TUSC3 gene in a consanguineous Pakistani family with autosomal recessive nonsyndromic intellectual disability}

Khan et al. 


\title{
A novel deletion mutation in the TUSC3 gene in a consanguineous Pakistani family with autosomal recessive nonsyndromic intellectual disability
}

\author{
Muzammil Ahmad Khan ${ }^{1,2}$, Muhammad Arshad Rafiq ${ }^{2}$, Abdul Noor ${ }^{2}$, Nadir Ali ${ }^{1}$, Ghazanfar Ali ${ }^{1,3}$, John B Vincent ${ }^{2,4}$ \\ and Muhammad Ansar ${ }^{1 *}$
}

\begin{abstract}
Background: Intellectual disability (ID) is a serious disorder of the central nervous system with a prevalence of 1$3 \%$ in a general population. In the past decades, the research focus has been predominantly on X-linked ID (68 loci and 19 genes for non syndromic $X$ linked ID) while for autosomal recessive nonsyndromic ID (NSID) only 30 loci and 6 genes have been reported to date.

Methods: Genome-wide homozygosity mapping with $500 \mathrm{~K} \mathrm{Nsp1}$ array (Affymetrix), CNV analysis, PCR based breakpoint mapping and DNA sequencing was performed to explore the genetic basis of autosomal recessive nonsyndromic ID in a large Pakistani family.

Results: Data analysis showed linkage at 8p23 locus with common homozygous region between SNPs rs6989820 and rs2237834, spanning a region of $12.494 \mathrm{Mb}$. The subsequent CNV analysis of the data revealed a homozygous deletion of $170.673 \mathrm{~Kb}$ which encompassed the TUSC3 gene.

Conclusion: We report a novel deletion mutation in TUSC3 gene which is the second gene after TRAPPC9 in which mutation has been identified in more than one family with autosomal recessive NSID. The study will aid in exploring the molecular pathway of cognition.
\end{abstract}

\section{Background}

Intellectual disability (ID), also frequently referred to as Mental Retardation or cognitive impairment (CI), is a condition where intelligence quotient is less than 70 , there is deficiency in at least two adaptive skills like communication, reading, writing, self care etc and onset before 18 year of age [1]. Assuming a population mean IQ of 100 , ID is subcategorized as mild (50-55 to 70), moderate (35-40 to 50-55), severe (20-25 to $35-40)$ and profound (below 20-25) [1,2].

Generally it is believed that $\sim 25 \%$ of genetic ID patients are thought to have autosomal recessive mode of inheritance [3]. To date 30 loci including six known genes have been reported to be involved in autosomal recessive NS-ID (ARNS-ID) [4]. These include PRSS12

\footnotetext{
* Correspondence: ansar@qau.edu.pk

'Department of Biochemistry, Quaid-i-Azam University Islamabad, Islamabad, Pakistan

Full list of author information is available at the end of the article
}

(Protease, Serine, 12 or Neurotrypsin; MIM\# 606709) [5], CRBN (Cereblon; MIM\# 609262) [6], CC2D1A (Coiled-coil and $\mathrm{C} 2$ domain containing protein $1 \mathrm{~A}$; MIM\# 610055) [7], GRIK2 (Glutamate receptor, ionotropic, kainite 2; MIM\#138244) [8], TUSC3 (Tumor suppressor candidate 3; MIM\# 601385) [9,10], TRAPPC9 (Trafficking protein particle complex subunit 9; MIM\# 611966) [11-13].

Chromosome 8 is considered an average chromosome with respect to size $(146.364 \mathrm{Mb})$, number of genes (1198), repeat content and degree of segmental duplication [14]. But its p arm showed high degree of sequence variations, particularly within its distal-most $\sim 15$ megabase region. This region is believed to be of prime importance in the human genome because of the high expression pattern of nervous system related genes, and has recently been touted as a "hub" for neuropsychiatric developmental disorders [15]. Many genomic imbalances on $8 \mathrm{p}$ locus, such as duplication of $8 \mathrm{p} 23.1-8 \mathrm{p} 22.2$, are
Ciomed Central

() 2011 Khan et al; licensee BioMed Central Ltd. This is an Open Access article distributed under the terms of the Creative Commons Attribution License (http://creativecommons.org/licenses/by/2.0), which permits unrestricted use, distribution, and reproduction in any medium, provided the original work is properly cited. 
associated with learning disability [16]. Also one gene for microcephaly (MCPH1) and one gene for NS-ID, namely TUSC3, have been identified on $8 \mathrm{p}$.

In this study we present the clinical and molecular analysis of a consanguineous Pakistani family with autosomal recessive NS-ID, and report a novel mutation comprising deletion of the entire TUSC3 gene (except for the promoter and $1^{\text {st }}$ exon) and its down stream region at the $8 \mathrm{p} 23$ locus.

\section{Methods}

\section{A: Sampling and DNA extraction}

The family was recruited from a rural part of Sindh province of Pakistan, after getting prior approval from Institutional Review Board (Quaid-I-Azam U IRB\#1Biomedical; IORG0002926; IRB00003532), and blood samples were taken from available affected and unaffected family members and DNA was extracted from whole blood by following the standard proteinase K/ phenol/chloroform isolation method. Written informed and photography consents (Translated in local Urdu language) were obtained from the parents/guardians of patients participating in this study, which conforms to Helsinki Declaration and local legislation.

\section{B: Clinical Assessments}

Affected family members were evaluated with the help of standard questionnaire (translated and amended version of Wechsler Intelligence Scale in Urdu) for severity of disease and IQ assessments. Photographs of affected members were taken with written consent to study and publish their facial features. Two individuals from two different loops of the pedigree were selected for cranial CT scan (IV-10 and IV-14) to screen for abnormal brain anatomical features. For information on disease onset, parents were interviewed about the prenatal, perinatal and neonatal medical history of the proband.

\section{C: Molecular Assessments (i) Genome-wide scan}

Whole Genome scan was performed by using Genechip Mapping 500K array NspI chip (Affymetrix) for four affected and 2 unaffected family members and the data was analyzed using dChip and HomozygosityMapper software for homozygosity mapping and copy number analysis $[17,18]$. After fine mapping the region in complete family data was analyzed with Merlin for twopoint and multipoint LOD score calculations. For this purpose pedigree was divided in to two loops to overcome size limitations of the Merlin.

\section{(ii) PCR based deletion break-point mapping}

To map the deletion breakpoints, primers were designed (for both upstream and downstream regions) between the deleted and intact SNPs identified from the microarray data, using Primer3 software (version 0.4.0) [19]. PCR was performed for both sets of primers, and only those sets (from both the distal and proximal regions) were selected that lie closest to the deleted SNPs and showed amplification. PCR was performed using a forward primer from the distal set and reverse primer from the proximal set to amplify the junction fragment. The junction fragment was then sequenced, and the exact physical co-ordinates were determined using the BLAT tool of the UCSC Genome Browser to align the sequence to the genome [20].

\section{Results}

\section{Clinical description}

The family under examination consisted of six affected individuals from three different extended branches (Figure 1) and who suffer from cognitive impairment with an IQ in the range of severe ID (25-35). Prenatal, perinatal and neonatal medical histories of all affected individuals were normal. Ophthalmological and otorhinolaryngological findings were also normal. Cranial computed tomography (CT) performed on the patients from two separate loops did not reveal any brain dysmorphology or neurologic symptoms (Data not shown). No facial dysmorphism was observed except for affected individual IV-10 who had strabismus (Figure 2). In individual IV-15 cognitive impairment was also accompanied by a form of muscular dystrophy, so this individual was not treated as affected for the purposes of the analysis which was later supported by the homozygosity and CNV data. The clinical information of the affected individuals (on the basis of questionnaire) is presented in Table 1.

\section{Molecular studies}

\section{(i) Genome-wide Homozygosity mapping and CNV analysis}

Genome wide homozygosity mapping revealed homozygosity-by-descent (HBD or autozygosity) among four affected individuals (IV-11, IV-12, IV-13) on 8p23 (Figure 3) between SNPs rs6989820 and rs2237834, which delineates a critical region of 12.494 Mb \{UCSC genome Browser, May 2004 (NCBI35/hg17)\}. In order to confirm segregation of the identified HBD region in the entire family STS markers D8S1781, D8S262, D8S518, D8S1140, D8S277, D8S351, D8S1469, D8S1721, D8S550, D8S552, D8S1106, D8S1790, D8S1731, D8S1145 and D8S298 were genotyped. Haplotypes were generated and are presented in Figure 1, which also indicate the segregation of a minimum critical region flanked by above mentioned SNPs. Linkage analysis yielded two-point and multipoint LOD scores above 3 and 5 respectively at several markers (Table 2). This region contained a total of 96 known genes \{UCSC Genome Browser, May 2004 (NCBI35/hg17)\} including 


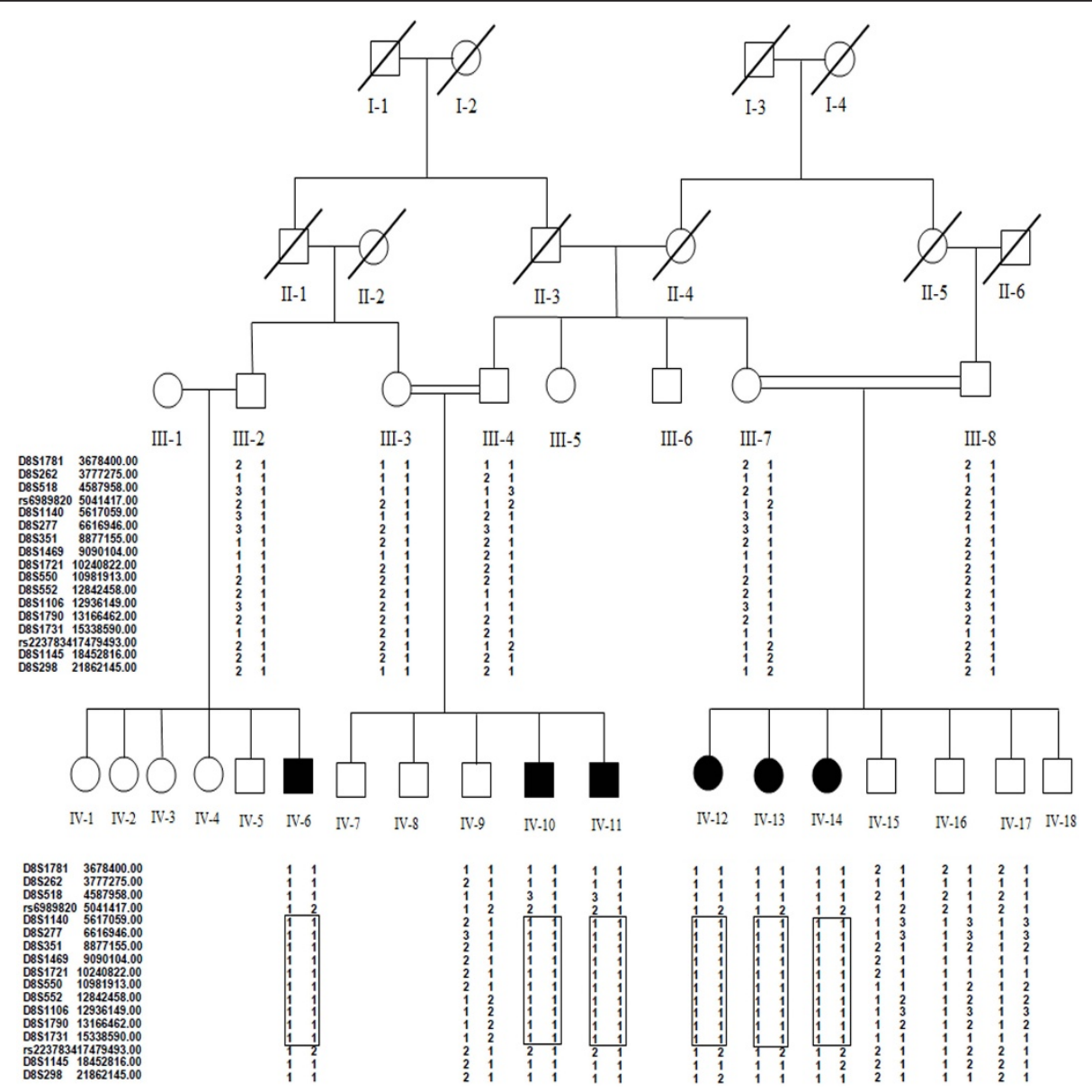

Figure 1 Pedigree of a Pakistani family segregating AR-NSID. Square represent male and circles female while black symbols represents affected individuals and clear symbols unaffected individuals. Autozygosity mapping was done for individuals IV-11, IV-12, IV-13 and IV-14. All affected individuals share a homozygous haplotype in the chromosome 8p23.1 region, which is shown in boxes. Markers with physical map distances are shown on the left side.

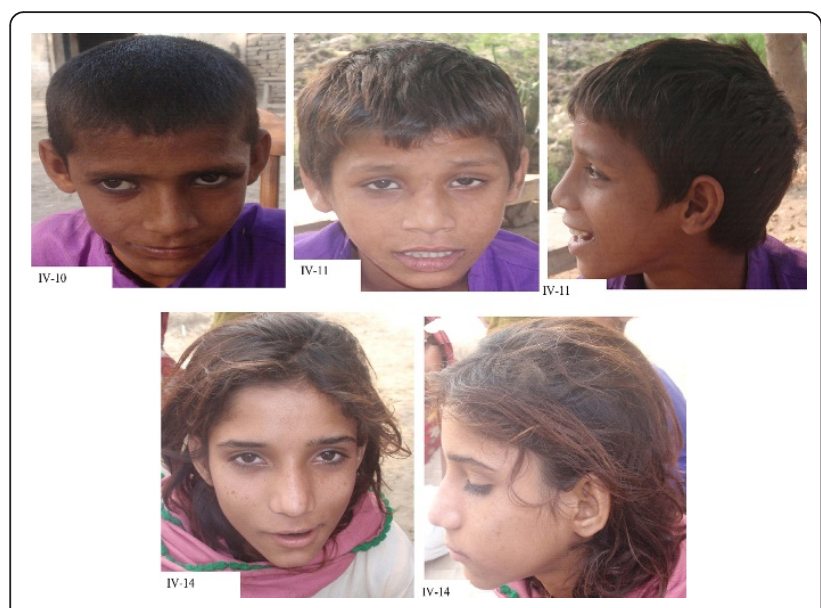

Figure 2 Facial pictures of patients with front and side pose; Individual IV-10 has a minor ophthalmic issue, whereas individuals IV-11, and IV-14 reveal no apparent dysmorphism.
MCPH1 and TUSC3, which have already been reported to be involved in microcephaly with ID. Initially $M C P H 1$ gene was sequenced to detect pathogenic mutation in this family but the sequence analysis only revealed the presence of known SNPs in exon 1 (rs2305023), 6 (rs2442513) and 8 (rs930557 and rs2920676). Subsequent CNV analysis of microarray data showed homozygous deletion of $170.673 \mathrm{~Kb}$ region in all affected individuals. The deletion encompassed almost the entire TUSC3 gene (minus the promoter and first exon) and its downstream region.

\section{(ii) Deletion breakpoint mapping}

The CNV analysis of microarray data revealed that in all affected individuals no hybridization signals were generated for 22 SNPs on chromosome 8; from rs4258002 to rs352769 as borderline deleted SNPs. With the evidence of microarray data of four affected individuals, size of deletion fragment was mapped by PCR amplification 
Table 1 Summary of the clinical data of affected individuals

\begin{tabular}{|c|c|c|c|c|c|c|}
\hline Clinical Findings & IV-12 & IV-14 & IV-13 & IV-6 & IV-10 & IV-11 \\
\hline Sex & Female & Female & Female & Male & Male & Male \\
\hline Age on assessment & 15 years & 10 years & 13 years & 18 years & 10 years & 11 years \\
\hline Developmental delay & + & + & + & + & + & + \\
\hline Head Circumference & 52 & $51 \mathrm{~cm}$ & 51 & Not Available & $52 \mathrm{~cm}$ & $50 \mathrm{~cm}$ \\
\hline Speech Development & + & + & + & + & + & + \\
\hline Dysmorphic feature & - & - & - & - & - & - \\
\hline Skeletal Problem & - & - & - & - & - & - \\
\hline Ophthalmological problem & - & - & - & - & - & - \\
\hline Epilepsy & - & + & - & - & - & - \\
\hline Mental retardation & Severe & Severe & Severe & Severe & Severe & Severe \\
\hline Growth & Normal & Normal & Weak & Normal & Normal & Normal \\
\hline Schooling & - & - & - & - & - & - \\
\hline Learning Disability & + & + & + & + & + & + \\
\hline Muscular dystrophy & - & - & - & - & - & - \\
\hline Self biting & - & - & - & - & - & - \\
\hline
\end{tabular}

Each column indicates the data of an individual and row presents the category of clinical symptoms, (- indicates absence, + indicates presence).

and sequencing of junction fragment by designing primer (forward primer 5 '-TGCTCTCTGCTCTTCCTC GT-3'; reverse primer: 5'-CTTTCCTGGCAAGCTGCT AC-3') between deleted and intact SNPs (between rs10094375 and rs4258002 towards the distal end, and rs352769 and rs6530906 proximally). The BLAT search for the junction fragment sequence against human genome revealed the actual physical co-ordinates of deletion as being between $15521688 \mathrm{bp}$ to $15692362 \mathrm{bp}$, and spanning a region of $170.673 \mathrm{~Kb}$. The deletion was also checked in all available family members by using TUSC 3 exon 3 and 5 and junction fragment primers. Both of these primer sets showed amplification in the normal individuals which represented the heterozygous segregation of this deletion except in individual IV-15. All the affected individuals of this family were homozygous for the deletion, and no homozygous or heterozygous deletion carriers were identified among 276 unrelated healthy Pakistani individuals. This deletion encompassed almost the entire TUSC3 gene (minus the

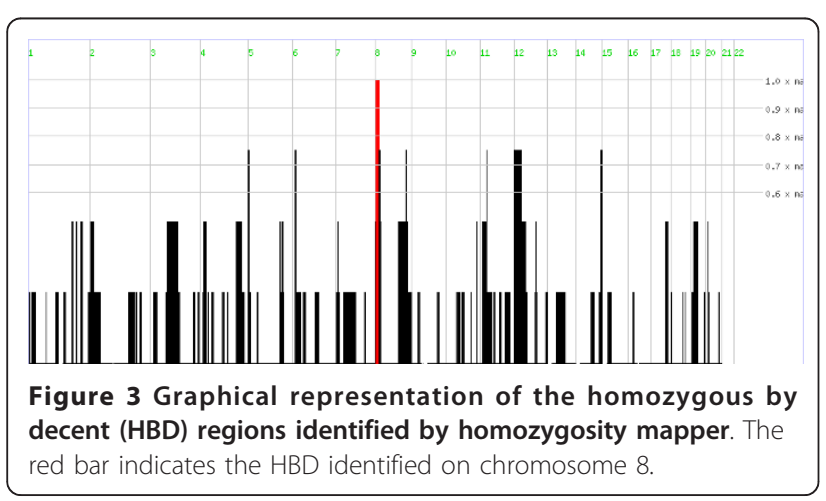

promoter and first exon) and its downstream region (Figure 4). According to the database of genomics variants [21] 57 CNVs have been reported in HBD region identified in this family, but 27 involve TUSC3 gene. The detailed analysis of the CNV data indicates that all

Table 2 Two point and multipoint LOD score between identified HBD and chromosome 8 markers

\begin{tabular}{|c|c|c|c|c|}
\hline Markers & $\begin{array}{l}\text { Genetic } \\
\text { Position in cM } \\
\text { (Rutgers map, } \\
\text { build } 36 \text { ) }\end{array}$ & $\begin{array}{l}\text { Physical Position } \\
\text { in bp }\{\text { Feb.2009 } \\
\text { (GRCh37/hg19\} }\end{array}$ & $\begin{array}{l}\text { Two } \\
\text { point } \\
\text { LOD } \\
\text { Score }\end{array}$ & $\begin{array}{l}\text { Multipoint } \\
\text { LOD Score }\end{array}$ \\
\hline D8S1781 & 6.8 & 3678400 & 2.2342 & 4.2286 \\
\hline D8S262 & 7.13 & 3777275 & 1.0814 & 4.2143 \\
\hline D8S518 & 9.88 & 4587958 & 0.5706 & 1.456 \\
\hline rs6989820 & - & 5041417 & -3.8284 & -4.0196 \\
\hline D8S1140 & 11.96 & 5617059 & 3.1114 & 2.9368 \\
\hline D8S277 & 14.92 & 6616946 & 2.9565 & 5.0000 \\
\hline D8S351 & 18.94 & 8877155 & 3.0286 & 5.1617 \\
\hline D8S1469 & 19.38 & 9090104 & 1.523 & 5.1693 \\
\hline D8S1721 & 19.7 & 10240822 & 1.8241 & 5.1717 \\
\hline D8S550 & 20.85 & 10981913 & - & - Infinity \\
\hline D8S552 & 24.76 & 12842458 & 2.9823 & 5.1646 \\
\hline D8S1106 & 24.76 & 12936149 & 3.2113 & 5.1646 \\
\hline D8S1790 & 26.35 & 13166462 & 3.2843 & 5.1229 \\
\hline D8S1731 & 27.95 & 15338590 & 1.3825 & 4.5748 \\
\hline rs2237834 & - & 17479493 & -3.8284 & -4.4686 \\
\hline D8S1145 & 32.78 & 18452816 & Infinity & - Infinity \\
\hline D8S298 & 40.11 & 21862145 & Infinity & - Infinity \\
\hline
\end{tabular}



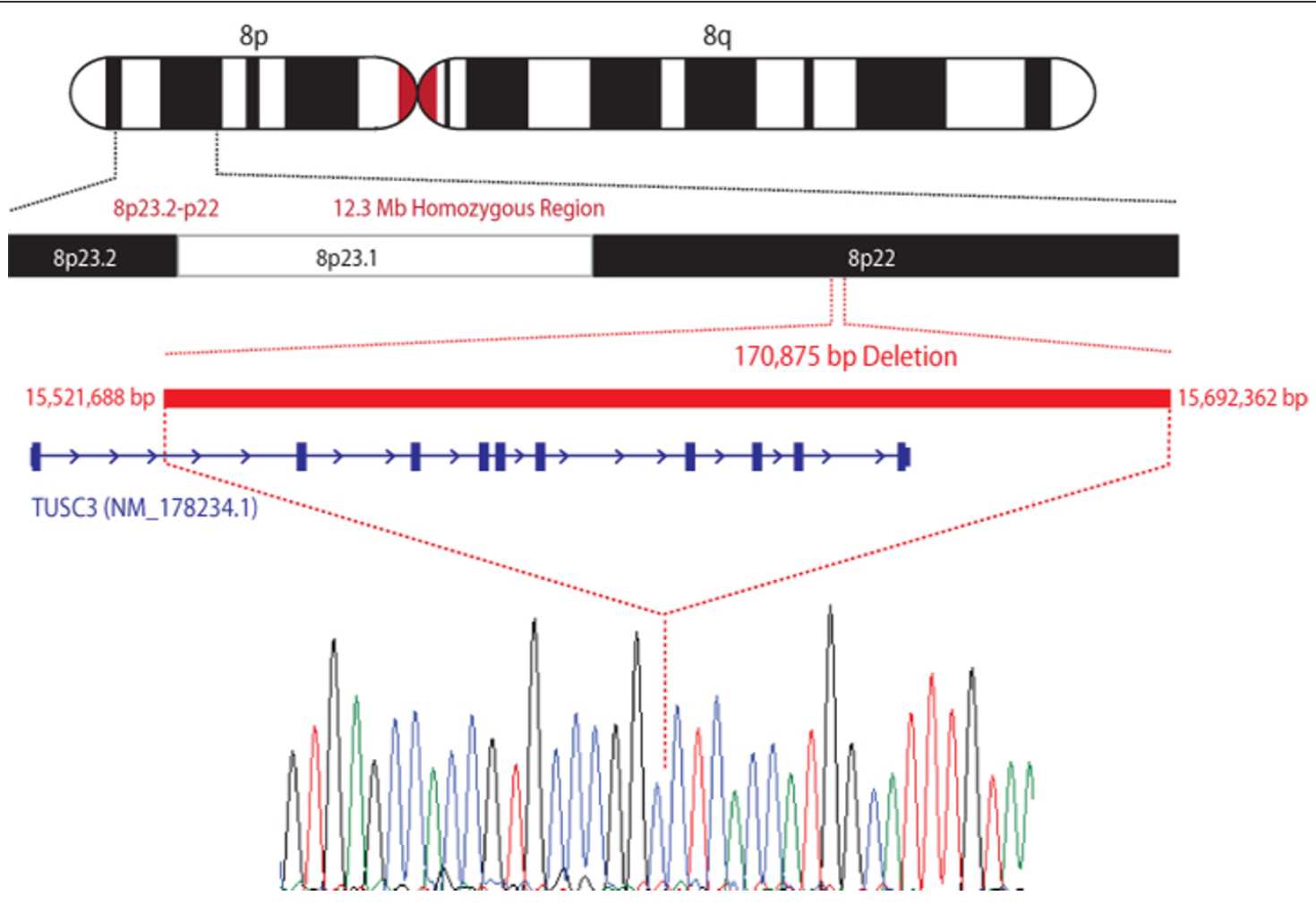

Figure 4 Ideogram depicting the $12.3 \mathrm{Mb}$ homozygous region on 8p23 locus. Red bar is representing total region of deletion which contains TUSC3 gene shown in blue color bar. The dotted line from red bar over the sequence chromatogram indicates the junction point.

the presently identified TUSC3 involving CNVs exist in heterozygous state.

\section{Discussion and Conclusion}

Autosomal recessive NSID accounts for $\sim 25 \%$ of genetic ID cases and may be more common than $\mathrm{X}$ linked cases, however, the molecular basis of AR-NSID is relatively poorly known because of clinical and genetic heterogeneity, and the absence of distinguishing clinical criteria. In non-syndromic ID, cognitive deficit is the sole clinical feature among the patients. It is suggested that ID may be caused by the disruption of the biological and molecular processes in the nervous system such as neuronal differentiation and synaptic plasticity, synaptic vesicles cycling and gene expression, regulation profiling etc [22]. There are number of co-translational and post-translational modifications required for protein stability and proper protein folding into its 3D structure, which are essential for normal protein function. One such post-translational modification, N-glycosylation, has previously reported to be involved in non-syndromic $\mathrm{X}$-linked ID at a TUSC3 paralogous gene, IAP [9].

In the current study we analyzed a four generation Pakistani family with 6 affected individuals having severe psychomotor developmental delay, segregating autosomal recessive mode of inheritance. The major clinical presentations of all patients were normal except for the cognitive dysfunction. However comparison of the clinical data (Biometric and neurological data) of our family with the patients of earlier reports did not reveal any significant difference in the phenotypic expression $[9,10]$. TUSC 3 is the $5^{\text {th }}$ gene in autosomal recessive NSID and the $2^{\text {nd }}$ in which a $3^{\text {rd }}$ mutation has been identified, after TRAPPC9. Our study will aid in diagnostic assessment of AR-NSID individuals.

\section{Acknowledgements}

We wish to thank all the members of this family for their voluntary participation and cooperation with this study. MAK was supported by Indigenous Scholarship and International Research Support Program (IRSIP) from the Higher Education Commission (HEC) of Pakistan. JBV is a National Alliance for Research on Schizophrenia and Depression Independent Investigator. This research was supported by grants from the HEC (NRPU1118), and the Canadian Institutes of Health Research (\#MOP-102758).

\section{Author details}

${ }^{1}$ Department of Biochemistry, Quaid-i-Azam University Islamabad, Islamabad, Pakistan. ${ }^{2}$ Molecular Neuropsychiatry \& Development Lab, Neurogenetics Section, Centre for Addiction and Mental Health, Toronto, ON, Canada. ${ }^{3}$ Center of Excellence in Biotechnology Research, King Saud University, Riyadh, Kingdom of Saudi Arabia. ${ }^{4}$ Department of Psychiatry, University of Toronto, Toronto, Ontario, Canada.

\section{Authors' contributions}

MAK did the DNA extraction, microarray data analysis, PCR based breakpoint mapping and sequencing of junction fragments, MAR and AN performed 
microarray data analysis, NA and GA recruited, sampled and done clinic work up while the project designing and funding was arranged by MA and JBV. All authors have read and approved the final manuscript.

\section{Competing interests}

The authors declare that they have no competing interests.

Received: 7 January 2011 Accepted: 22 April 2011

Published: 22 April 2011

\section{References}

1. American Psychiatric Association: Diagnostic and Statistical Manual of Mental Disorders. American Psychiatric Association, Washington; Fourth 2000, Text Revision.

2. WHO: The ICD-10 classification of mental and behavioral disorders. WHO; 1992.

3. Bartley JA, Hall BD: Mental retardation and multiple congenital anomalies of unknown etiology: frequency of occurrence in similar affected sibs of the proband. Birth Defects Orig Artic Ser 1978, 14:127-137.

4. OMIM database. [http://www.ncbi.nlm.nih.gov/omim/].

5. Molinari F, Rio M, Meskenaite V, Encha-Razavi F, Auge J, Bacq D, Briault S, Vekemans M, Munnich A, Attie-Bitach T, Sonderegger P, Colleaux L: Truncating neurotrypsin mutation in autosomal recessive nonsyndromic mental retardation. Science 2002, 298:1779-1781.

6. Higgins JJ, Pucilowska J, Lombardi RQ, Rooney JP: A mutation in a novel ATP-dependent Lon protease gene in a kindred with mild mental retardation. Neurology 2004, 63:1927-1931.

7. Basel-Vanagaite L, Attia R, Yahav M, Ferland RJ, Anteki L, Walsh CA, Olender T, Straussberg R, Magal N, Taub E, Drasinover V, Alkelai A, Bercovich D, Rechavi G, Simon AJ, Shohat M: The CC2D1A, a member of a new gene family with $\mathrm{C2}$ domains, is involved in autosomal recessive non-syndromic mental retardation. J Med Genet 2006, 43:203-210.

8. Motazacker MM, Rost BR, Hucho T, Garshasbi M, Kahrizi K, Ullmann B, Abedini SS, Nieh SE, Amini SH, Goswami C, Tzschach A, Jensen LR, Schmitz D, Ropers HH, Najmabadi H, Kuss AW: A defect in the ionotropic glutamate receptor 6 gene (GRIK2) is associated with autosomal recessive mental retardation. Am J Hum Genet 2007, 81:792-798.

9. Garshasbi M, Hadavi V, Habibi H, Kahrizi K, Kariminejad R, Behjati F, Tzschach A, Najmabdi H, Ropers HH, Kuss AW: A defect in the TUSC3 gene is associated with autosomal recessive mental retardation. Am J Hum Genet 2008, 82:1158-1164.

10. Molinari F, Foulquier F, Tarpey PS, Morelle W, Boissel S, Teague J, Edkins S, Futreal PA, Stratton MR, Turner G, Matthijs G, Gecz J, Munnich A, Colleaux L: Oligosaccharyltransferase-subunit mutations in nonsyndromic mental retardation. Am J Hum Genet 2008, 82:1150-1157.

11. Mir A, Kaufman L, Noor A, Motazacker MM, Jamil T, Azam M, Kahrizi K, Rafiq MA, Weksberg R, Nasr T, Naeem F, Tzschach A, Kuss AW, Ishak GE, Doherty $\mathrm{D}$, Ropers $\mathrm{HH}$, Barkovich AJ, Najmabadi $\mathrm{H}$, Ayub M, Vincent JB: Identification of mutations in TRAPPC9, which encodes the NIK- and IKKbeta-binding protein, in nonsyndromic autosomal-recessive mental retardation. Am J Hum Genet 2009, 85:909-915.

12. Mochida GH, Mahajnah M, Hill AD, Basel-Vanagaite L, Gleason D, Hill RS, Bodell A, Crosier M, Straussberg R, Walsh CA: A truncating mutation of TRAPPC9 is associated with autosomal-recessive intellectual disability and postnatal microcephaly. Am J Hum Genet 2009, 85:897-902.

13. Philippe O, Rio M, Carioux A, Plaza JM, Guigue P, Molinari F, Boddaert N, Bole-Feysot C, Nitschke P, Smahi A, Munnich A, Colleaux L: Combination of linkage mapping and microarray-expression analysis identifies NFkappa-B signaling defect as a cause of autosomal-recessive mental retardation. Am J Hum Genet 2009, 85:903-908.

14. Nusbaum C, Mikkelsen TS, Zody MC, Asakawa S, Taudien S, Garber M, Kodira CD, Schueler MG, Shimizu A, Whittaker CA, Chang JL, Cuomo CA, Dewar K, FitzGerald MG, Yang X, Allen NR, Anderson S, Asakawa T, Blechschmidt K, Bloom T, Borowsky ML, Butler J, Cook A, Corum B, DeArellano K, DeCaprio D, Dooley KT, Dorris L, Engels R, Glöckner G, Hafez N, Hagopian DS, Hall JL, Ishikawa SK, Jaffe DB, Kamat A, Kudoh J, Lehmann R, Lokitsang T, Macdonald P, Major JE, Matthews CD, Mauceli E, Menzel U, Mihalev AH, Minoshima S, Murayama Y, Naylor JW, Nicol R, Nguyen C, O'Leary SB, O'Neill K, Parker SC, Polley A, Raymond CK Reichwald K, Rodriguez J, Sasaki T, Schilhabel M, Siddiqui R, Smith CL, Sneddon TP, Talamas JA, Tenzin P, Topham K, Venkataraman V, Wen G,
Yamazaki S, Young SK, Zeng Q, Zimmer AR, Rosenthal A, Birren BW, Platzer M, Shimizu N, Lander ES: DNA sequence and analysis of human chromosome 8. Nature 2006, 439:331-335.

15. Tabarés-Seisdedos R, Rubenstein JL: Chromosome $8 p$ as a potential hub for developmental neuropsychiatric disorders: implications for schizophrenia, autism and cancer. Mol Psychiatry 2009, 14:563-89.

16. Glancy M, Barnicoat A, Vijeratnam R, de Souza S, Gilmore J, Huang S, Maloney VK, Thomas NS, Bunyan DJ, Jackson A, Barber JC: Transmitted duplication of 8p23.1-8p23.2 associated with speech delay, autism and learning difficulties. Eur I Hum Genet 2009, 14:37-43.

17. Li C, Wong WH: Model-based analysis of oligonucleotide arrays: Expression index computation and outlier detection. Proc Natl Acad Sci 2001, 98:31-36.

18. Seelow D, Schuelke M, Hildebrandt F, Nürnberg P: HomozygosityMapperan interactive approach to homozygosity mapping. Nucleic Acids Res 2009, 37:W593-599.

19. Primer3 software (version 0.4.0). [http://frodo.wi.mit.edu/primer3/].

20. UCSC Genome Browser. [http://genome.ucsc.edu/].

21. Database of genomic Variations. [http://projects.tcag.ca/variation/].

22. Basel-Vanagaite L, Taub E, Halpern GJ, Drasinover V, Magal N, Davidov B, Zlotogora J, Shohat M: Genetic screening for autosomal recessive nonsyndromic mental retardation in an isolated population in Israel. Eur J Hum Genet 2007, 15:250-253.

\section{Pre-publication history}

The pre-publication history for this paper can be accessed here: http://www.biomedcentral.com/1471-2350/12/56/prepub

doi:10.1186/1471-2350-12-56

Cite this article as: Khan et al: A novel deletion mutation in the TUSC3 gene in a consanguineous Pakistani family with autosomal recessive nonsyndromic intellectual disability. BMC Medical Genetics 2011 12:56.

\section{Submit your next manuscript to BioMed Central and take full advantage of:}

- Convenient online submission

- Thorough peer review

- No space constraints or color figure charges

- Immediate publication on acceptance

- Inclusion in PubMed, CAS, Scopus and Google Scholar

- Research which is freely available for redistribution

Submit your manuscript at www.biomedcentral.com/submit
C Biomed Central 